\title{
Food safety and network governance structure of the agri-food system
}

\author{
Miroslava Bavorová • Norbert Hirschauer • \\ Gaetano Martino
}

Published online: 1 December 2013

(C) Springer Science+Business Media New York 2013

\section{The problem background of food quality and safety}

Over the last decades, citizens, consumers and policy makers have become increasingly concerned about the challenges related to the agri-food system such as food security, food quality and safety, the free and informed choice of consumers, animal welfare, environmental protection and the mitigation of climate change. Troubled by the negative externalities of food production, as well as the occurrence of a great number of incidents including food law offences and fraudulent behaviour, consumers and policy makers call for more efforts to identify the failures in food markets and mitigate the corresponding credence quality problems and food risks. Hazards and food quality threats may arise at all levels of the food supply system, and safety precautions and controls may fail due to technological flaws and human errors or misbehaviours on any of these levels.

Since food quality and safety depend on all members of the food supply chain, improving the chain's quality and safety performance requires collective action and the design of governance structures which facilitate organizational choices that overcome the information and coordination problems within the supply chain. In relation to the self-organization of food businesses, the general governance perspective can be related to private contracts and supply chain management. Supply chain management is about providing/sharing resources and aligning the activities of different supply chain members in order to reduce chain costs and increase chain benefits that can be distributed among the chain members (cf., Arshinder and Deshmukh 2008). In other words: technological and behavioural uncertainties may induce food businesses to make voluntary multi-lateral agreements and allocate

\footnotetext{
M. Bavorová · N. Hirschauer $(\bowtie)$

Martin-Luther-University Halle-Wittenberg, Halle, Germany

e-mail: norbert.hirschauer@landw.uni-halle.de

G. Martino

University of Perugia, Perugia, Italy
} 
resources to systems that channel information along the chain and favour the coordination among chain members (cf., Hammoudi et al. 2009; Hobbs 2004; Martino and Perugini 2006; Ménard and Valceschini 2005; Unnevehr and Jenson 1999).

The last decades have also seen the change from a local and/or national level to a global level food supply system. The main drivers of this change are the removal of trade barriers, technological innovation, economies of scale, and steadily increasing demands on food quality, diversity and year-round availability. At present, food production and distribution is governed by a multi-level network of various governmental and non-governmental actors, including food authorities, market participants, business associations and special interest groups, i.e., a system of public and private institutions that support and regulate economic activities and transactions. Following Braithwaite et al. (2007), we conceive regulation as a narrower term than governance. Whereas governance is about providing, distributing and regulating, "regulation can be conceived as that large subset of governance that is about steering the flow of events and behaviour, as opposed to providing and distributing. Of course, when regulators regulate, they often steer the providing and distributing that regulated actors undertake" (Braithwaite et al. 2007: 3).

Besides international food safety and trade agreements, four major types of regulator-regulatee relationships can be distinguished within the network structure of the agri-food system: first, the various buyer-seller dyads along the food chain (including the relationship between dominant chain actors and other chain members), second, the relationship between food authorities and food businesses on various chain levels, third, the relationship between food authorities and consumers, and fourth, the relationship between food consumers/citizens and governments. In the network structure of the agri-food system, every entity-be it a food safety authority, a food business or the food consumer-is both a regulating actor who aims to steer the behaviour of others, and a regulated actor whose behaviour is subject to steering efforts by other stakeholders.

Due to the pre-eminent role of food businesses for food quality and safety, mitigating market failures and corresponding food risks requires effective and cost-efficient regulations that reduce information asymmetries and make businesses internalize externalities. In this context, we need to abandon a perspective that focuses exclusively on the regulation of food businesses by governments. Instead, we need to understand that the food businesses in the supply chain are subjected to co-regulation, i.e., a mix of public and private regulatory measures. The steering efforts of public bodies (sometimes termed: "corporate regulation") are predominantly associated with law-making and legal sanctions, whereas the steering efforts of private actors (sometimes termed: "relationship management") are usually linked to private contracts and liabilities. The underlying objective is, however, identical: the party with the coarser information partition tries to manage behavioural risks and steer behaviour.

\section{Behavioural determinants and regulatory regimes}

The regulatory mechanisms that are used to steer behaviour have impacts on one or several of the following behavioural determinants: first, the set of choices that is 
available to the actors, second, the material incentives they are exposed to, third, the social and psychological rewards and costs resulting from their choices (e.g., social respect, ostracism, self-esteem, guilt), and fourth, their individual abilities and capacities.

Depending on the type of the behavioural determinant they are primarily intended to impact, four ideal types of regulatory regimes can be distinguished:

1. Hierarchical command and control measures, such as effectively imposed and enforced mandatory rules, impact on the set of choices (e.g., through the withdrawal of the operating licence), as well as on the material incentives (e.g., through legal sanctions).

2. Incentive-oriented mechanisms, such as price rises and cuts, Pigouvian taxes, government payments, liabilities, and the creation of novel property rights and markets, change the relative prices attached to individual actions without resorting to command and control in terms of behavioural prescriptions.

3. Measures strengthening bonds to social norms, such as the promotion of corporate social responsibility through persuasion and "re-integrative shaming" (cf., Braithwaite 2003), are aimed at changing the actors' social and psychological rewards and costs, i.e., their non-material extrinsic and intrinsic motivation. Through market reputation and consumer response, socially responsible behaviour may also impact the actors' material incentives.

4. Human capacity building measures, such as the provision of information, counselling and training, are aimed at enhancing the actors' abilities to adopt the desired behavioural change and act according to the regulator's wishes. Capacity building measures have also an impact on material incentives: the better informed and trained, the smaller the costs of adoption.

With its focus on law-enforcement and public regulation, criminology provides an alternative way of classifying regulatory regimes. In the words of Murphy (2008: 113), one can state that there is a division "between those who think that individuals and firms will comply with rules and regulations only when confronted with harsh sanctions and penalties, and those who believe that gentle persuasion and cooperation works in securing compliance." In addition to physical incapacitation and target hardening, this antithetic pairing has been labelled the deterrence versus accommodative model of regulation (cf., Picciotto and Campbell 2002).

While incentives are not always the primary focus, most regulatory regimes have an impact on the actors' incentive situation via some sort of sanctioning mechanism. According to Williamson (1985), incentives are influenced by "legal ordering" (legal sanctions for law-breakers) and "private ordering" (e.g., pledges and guarantees that are used for the ex post sanctioning of rule-breaking/opportunistic behaviour). More precisely, we can distinguish formal sanctions based on administrative law (e.g., administrative fines), criminal law (e.g., criminal penalties), civil code/tort law (e.g., damages) and private contracts (e.g., contractual fines) from informal sanctions. In transparent markets, informal sanctions arise in the form of opportunity costs that are caused by the negative reactions of market partners after the disclosure of opportunistic behaviour (e.g., reduced sales caused by a loss of reputation). 
There is no exclusive relationship which links certain types of regulators (e.g., public or private) to particular types of regulatory regimes (e.g., command and control vs. incentives). Food authorities regulate through mandatory law, as well as via incentives, bonds to norms and human capacity building. Public disclosure systems such as name-and-shame (cf., Bavorová and Hirschauer 2012), for instance, are co-regulatory mechanisms that explicitly combine public food law, food inspection and legal sanctions with an appeal to professional ethics, social pressure and a decisive change of material incentives brought about by the reputational sanctioning of private actors (e.g., a negative market response by consumers after disclosure of misconduct). A mix of regulatory mechanisms is also used by private firms. While they are mostly seen as relying on hierarchical command and control mechanisms within the firm, and on market incentives for inter-firm transactions, regulatory mixtures are used in both situations: within firms, incentive-based payment schemes complement command and control in many cases, and in the presence of product quality uncertainty inter-firm transactions are often characterized by tight contractual arrangement that are close to command and control approaches. In brief, we may state that all food businesses are co-regulated by a mixed group of public and private regulators, all of which rely on a mixture of regulatory mechanisms. Real-life food production contexts differ both in the intensity of regulation and the relative importance that can be attributed to diverse regulators and regulatory mechanisms. Using the term "contract" in a wide sense as "defining the rules of the game" (be it through voluntary agreements or through the unilateral directives of a dominant regulator), one could also understand and analyze regulation and organization as contractual choice issues (cf., Williamson 1985).

While the knowledge of the factors that determine the behaviour of food businesses is crucial for our understanding of the regulatory status quo and the identification of existing food quality and safety problems (cf., Hirschauer and Zwoll 2008), it is equally important to understand the dynamic shifts of extrinsic and intrinsic motivation brought about by regulatory change (regulatory innovation). Taken separately, one might assume that the more a regulatory measure generates material incentives to comply with the regulator's wishes, the more the regulatee's inclination to do so will increase (cf., Widdows 2000). Behavioural economics, however, inform us that the ceteris paribus assumption implicitly made in such a perspective is rarely in line with reality. Instead, the following interactions between extrinsic and intrinsic motivations may occur:

- Regulatory change may succeed in simultaneously increasing the actor's extrinsic and intrinsic motivation to act in accordance with the regulator's wishes or rules. Such a desirable interdependency has been termed "crowdingin" (cf., e.g., Frey 1997).

- Regulatory change, such as new controls, monetary rewards or sanctions, may change the relative competitiveness of individual action and increase the extrinsic motivation to comply, but intrinsic motivation may be impaired. As a consequence, the positive effect on behaviour may be less pronounced than what would be expected from a partial perspective that focuses exclusively on the extrinsic motivation. The balance of the desired change in behaviour may even 
be reduced to zero or become negative. Such dysfunctional effects have been termed "crowding-out" (cf., e.g., Frey 1997).

- Positive intrinsic motivation may eventually not only be impaired or reduced to zero, but regulatees may consider new regulations (e.g., costly new standards) as an illegitimate interference with their freedom of action. Such a lack of value correspondence (cf., Tyler 2006) between regulator and regulatees may produce defiance and reactance (cf., Miron and Brehm 2006) that give rise to a genuine intrinsic motivation not to comply. If so, regulatees may even accept economic disadvantages to regain their freedom of action by breaking the rules that they consider illegitimate.

Frey and Jegen (2001: 590) describe crowding-out as "one of the most important anomalies in economics, as it suggests the opposite of the most fundamental economic 'law', that raising monetary incentives increases supply." One would certainly have to integrate reactance into this statement. It should be noted, however, that the "anomaly" dissolves if, instead of maintaining a narrow rational choice assumption of wealth maximization, one adopts the broad utilitarian view that people pursue multiple goals and that human behaviour is shaped by a mixture of motivations (cf., Pinstrup-Andersen 2005).

\section{Smart regulation and regulatory impact analysis}

In its 2010 Communication on "Smart Regulation in the EU" (European Commission 2010), the European Commission launched an explicit smart regulation agenda and emphasized the continuing need for regulatory improvements. In its subsequent Communication on "EU Regulatory Fitness" (European Commission 2012), the Commission evaluated the progress that had been achieved in the past and outlined how regulation is to achieve its objectives even more effectively and efficiently in the future. From the viewpoint of a public regulator, such as national governments or the EU, smart regulation must be in line with the theory of market failure; i.e., the design of sensible regulatory intervention requires a thorough analysis of externalities and any intervention should be aimed at eliminating the identified externality as close to its origin as possible. Otherwise, a substantial risk arises that market failures are exchanged for government failures. If markets are failing due to information asymmetries and a lack of transparency, for instance, the reduction/elimination of that information asymmetry should be the regulatory objective.

The regulation of food businesses will only be smart if it meets two conditions: first, regulatory strategies can only be applied successfully if they are viable within a nation's legal and constitutional environment. Second, smart regulation has to be effective in that it changes the behaviour of food businesses in a significant way and in the direction intended by the regulator. From the perspective of a food authority, effective strategies are those that produce compliant behaviour, thus improving food quality and safety and guaranteeing the free and informed choice of consumers. To be effective, regulation must be based on a realistic behavioural model in which the 
relationships between the actors' behavioural determinants and their behaviours are adequately considered. Instead of focusing exclusively on material incentives, this requires a holistic approach which is aware of crowding-out and reactance problems and consistently combines measures that reduce misdirected incentives with measures that strengthen the actors' bonds to social norms (cf., Frey and Jegen 2001; Ostrom and Walker 2003). Any attempt to make an isolated impact on material incentives runs the risk of backfiring. Adopting a broad utilitarian view according to which human behaviour depends on multiple motivations, such a holistic approach can be understood as a strategy which aims to get the utilities right that are subjectively expected by multiple-goal and eventually bounded-rational actors. The conception of economic man underlying the change from the famous "get incentives right" to the more adequate "get utilities right" is the key to understanding what the regulatory issue is essentially about (Hirschauer et al. 2012).

The obvious and comprehensible focus of the Commission's smart regulation agenda is public regulation and, more specifically, EU legislation. However, each regulator-be it a public or a private one, and be it in the food industry or another sector of the economy-should be interested in the output (i.e., the change in behaviour) and the outcome (e.g., the change of food quality and safety) that a regulatory innovation is likely to induce. In other words, the design of a regulatory system which is consistent with the regulator's objectives requires a reliable regulatory impact analysis.

In a fully comprehensive regulatory impact analysis, the whole set of functional relations as depicted in Fig. 1 would need to be analyzed along the entire food chain. In other words, a full-scale cost-benefit analysis would be necessary, based on a thorough estimation of the costs of different regulatory systems, as well as a monetary evaluation of regulatory benefits (cf. e.g. Gunningham et al. 1999; Kirkpatrick and Parker 2007).

To reduce complexity, regulatory analysts often discard full-scale cost-benefit analyses and settle for partial analyses. That is, they confine themselves to studying selected subsets of the functional relationships depicted in Fig. 1. Willingness-topay analyses, for instance, are limited to the monetary evaluation of given physical outcomes. Transaction cost analyses focus on the cost side of regulatory systems and organizational arrangements. Regulatory cost-effectiveness analyses, in contrast, compare the costs of regulatory change either with the incurred change in behaviour or the physical outcome, both of which are measured with a nonmonetary yardstick. While doing without a monetary evaluation of regulatory benefits, the methodological requirements of cost-effectiveness analyses remain challenging, especially if they are so extensive as to measure the achievement of physical objectives. Besides the assessment of regulatory costs, two complex functional relationships need to be clarified in such an extensive analysis: first, one

\section{COSTS $\leftarrow$ Regulatory choice $\rightarrow$ Regulatees' behaviour $\rightarrow$ Physical outcome $\rightarrow$ BENEFITS}

Fig. 1 Functional relationships in a comprehensive regulatory impact analysis 
needs to answer the question of which behaviours are likely to be caused by the interventions under investigation (e.g., incentive payments for a reduction of nitrogen use in crop farming vs. mandatory standards). Second, one needs to study how these behaviours impact the regulator's physical objective (e.g., the intended nitrogen reduction in drinking water).

It cannot be emphasized enough that the understanding of the relationship between regulatory measures and the actors' behaviour is a sine qua non for providing meaningful decision support for the regulator. In other words, the core question of any regulatory impact analysis is what behavioural changes are likely to result from which regulatory measures. If the regulator has predefined a "desired behaviour" (e.g., compliance with food hygiene rules), and if we assume that more compliance dominates less compliance with regard to the regulator's final benefits, we may attempt an operational definition of "smart regulation" by resorting to a cost-effectiveness analysis that is concerned with behavioural effects. Due to informational constraints, regulators will rarely be able to identify the cost-efficient set of regulatory measures. Instead, they will be limited to conceiving and analyzing a limited number of discrete regulatory alternatives which may or may not belong to the cost-efficient set. Hence, we should exchange the futile quest for smart regulation with the more realistic search for smart regulatory change. Figure 2 illustrates the conceptual background and describes the corresponding possibilities to obtain an operational definition of smart regulatory change.

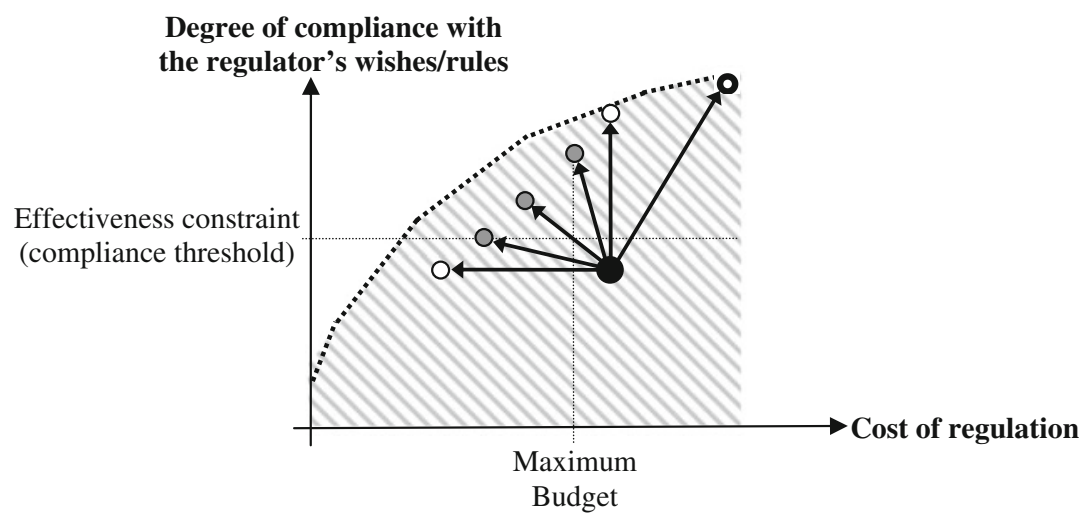

Unknown set of cost-efficient regulatory strategies

Unknown set of strategies that are dominated by the set of cost-efficient strategies

Regulatory status quo

○ Discrete set of smart regulatory changes compared to the status quo

- Discrete subset of smart regulatory changes that keep within a reduced maximum budget and meet an increased minimum effectiveness constraint

- Non-dominant regulatory change whose smartness can only be assessed after a monetary evaluation of regulatory benefits

Fig. 2 Smart regulatory change 
Smart regulatory change can be conceived as a relative concept based on the comparative method and the dominance principle. Correspondingly, we qualify a regulatory change as smart if it dominates the regulatory status quo, i.e., if it produces more compliant behaviour at identical or lower regulatory costs, or if it produces an identical amount of compliance at lower costs. The set of regulatory innovations that come into consideration may be limited by two additional factors: first, the regulator's choices may be constrained by a pre-defined budget that is smaller than the budget in the status quo. Second, the regulator may have defined a compliance threshold (minimum effectiveness constraint) that further reduces the choice set which comes into question. For the sake of completeness, one should add that some regulatory alternatives may increase the level of compliance but incur higher regulatory costs. The relative competiveness of such non-dominant changes (their smartness) can only be evaluated after the outcome (e.g., the reduction of hospitalizations due to food poisoning) has been approximately mapped into monetary units.

\section{Contributions to the special issue}

Against the background of a pervasive and ever more important search for better governance and regulatory improvements in the agri-food system, this Special Issue is aimed at consolidating knowledge regarding the functioning and performance of network governance and regulation structures. The papers in this issue address public regulation and the regulatory efforts of private actors in equal measure. One paper is explicitly concerned with the comparison between private and public regulation. While each contribution focuses on different aspects and fields, and while each of them uses a different approach, they make in their entirety a significant contribution to a more complete understanding of networked regulation in the global agri-food system. We thus hope and believe that both practitioners and scholars who have an interest in food regulation will benefit from this issue.

In the first article titled "Novel food for thought", Neuwirth explores the problem that regulation needs to be adapted on multiple levels to the fast, drastic and continuing changes in the world's food production without compromising the integrity and predictability of the law over time. Focusing on what he calls the "creative food economy" and the production of novel food as engineered by the use of bio- and nanotechnologies, the author concerns himself with the adaptation requirements on the international and domestic levels, the latter being exemplified by the situation in the EU and the People's Republic of China. Neuwirth identifies deficiencies in the institutional design of the current legal framework and concludes that, globally, there is a "regulatory mess" which is manifested in the fragmentation of international law, as well as in the lacking of consistency between general international law and trade law, between public international law and private international law, and, ultimately, between the international regime and the many divergent national legal systems.

The second article, by Desquilbet and Poret, is concerned with coexistence regulations for GM and non-GM crops. The authors use a formal economic model to 
analyse how the joint imposition of mandatory ex ante safety regulations and ex post liability rules on the producers of GM crops affect markets and welfare. Starting from the fact that GM labelling has become mandatory on the premise that consumers have a right to information and, in accordance with the predominant consumer preference in the European Union, Desquilbet and Poret assume that GM products are considered as inferior goods by consumers. Due to imminent gene flows from GM to non-GM fields, the cultivation of GM crops generates negative externalities for non-GM crop producers who strive to prevent commingling above the labelling threshold to prevent harvest downgrading. As a result of their formal model, the authors find that the combination of mandatory ex ante safety measures (isolation distances) and ex post compensations in case of damage may encourage the coexistence of GM products and non-GM products on the market while minimizing social welfare losses.

The third article, by Fagotto, resorts to law and economics to identify the comparative strengths and weaknesses of public, as opposed to private, food safety regulation. Fagotto studies whether private standards, which are so widespread that they have become de facto mandatory for many suppliers, can achieve the publicinterest objective to protect consumers' health. She furthermore asks whether private standards are substitutes or valuable complements of public regulation. Fagotto argues that private food standards tend to facilitate compliance for three reasons: first, they induce food businesses to use their unique internal capacity and knowledge to detect and manage internal risks. Second, they make food businesses undergo periodic audits which are more frequent than random government inspections. Third, they generate strong economic incentives to comply since food businesses want to secure market access. Due to the very fact that they are private in nature, private standards also have shortcomings. They are negotiated and applied without much public scrutiny and may privilege private interests over consumer protection. Furthermore, their enforcement relies on third-party certifiers who may be captured by the firms they should audit.

In the fourth paper, Rouvière and Latouche analyze how liability rules for food safety deficiencies affect the coordination in the food supply chain. Against the background of the implementation of the European General Food Law into national law, they study provisioning decisions of French retailers who sell fresh Spanish produce. The authors focus on the transfer of liability. In France, the first supplier who places products on the domestic market bears the liability. Import decisions at the French border are thus crucial indicators to understand how the liability rule shapes the supply chain. Retailers are confronted with a make-or-buy decision. They can import fresh products themselves and bear the liability (make option), or they can use an importer and thus delegate the liability (buy option). The authors show that in the wake of the regulatory change in 2005 (i.e., the introduction of the liability regime), French supermarkets have increasingly transferred the liability risk to importers. They also find that the regulatory change has prompted French importers of fresh produce to develop a horizontal and collective governance structure to ensure quality and safety.

In the last contribution to this issue, Cafaggi and Iamicelli concern themselves with transnational contracts and agreements in global food supply chains. They 
focus on agreements which combine regulatory safety and sustainability provisions with certification arrangements. The incorporation of certification regimes is understood as a special form of contractual design adopted by supply chain actors to overcome the weaknesses of conventional bilateral contracts. The authors argue that conventional contracts between individuals tend to be product-oriented and reactive approaches that are predominantly aimed at redressing the victim for damage suffered after a breach of contract. Agreements that combine regulatory provisions with certification obligations, in contrast, are seen as process-oriented and proactive approaches that account for the interdependence of contractual relationships along the whole chain and that are mainly aimed towards the prevention of contract breaches.

\section{Closing words}

Emphasizing the knowledge gaps and the continuing need for more regulatory research both in the food industries and other domains, we would like to conclude our introductory editorial by quoting some words of Braithwaite et al. (2007: 4) that have already inspired our endeavours as editors: "[...] we should not be surprised that innovations in networked regulation capture the imagination of big thinkers and practical doers alike about the direction the world is heading. [...] we see the promotion of better regulatory studies as a worthy way of understanding and improving the world around us. Bad regulation, after all, can do terrible damage to people. Good regulation can control problems [...]. Regulation matters, and therefore the development and empirical testing of theories about regulation also matter. Because regulation and regulatory studies make a crucial difference in the lives of millions of people, all of us in the intellectual community of regulatory scholars need to become more demanding than we have been about theoretical rigor and empirical evidence."

\section{References}

Arshinder, K. A., \& Deshmukh, S. G. (2008). Supply chain coordination: perspectives, empirical studies and research directions. International Journal of Production Economics, 115, 316-335.

Bavorová, M., \& Hirschauer, N. (2012). Producing compliant business behaviour: Disclosure of food inspection results in Denmark and Germany. Journal of Consumer Protection and Food Safety, 7, 45-53.

Braithwaite, J. (2003). Restorative justice and corporate regulation. In E. Weitekamp \& H.-J. Kerner (Eds.), Restorative justice in context: International practice and directions (pp. 161-172). Devon: Willan Publishing.

Braithwaite, J., Coglianese, C., \& Levi-Faur, D. (2007). Can regulation and governance make a difference? Regulation and Governance, 1, 1-7.

European Commission (2010). Smart regulation in the European Union. Communication from the commission to the European Parliament, the council, the European economic and social committee and the committee of the regions. http://eur-lex.europa.eu/LexUriServ/LexUriServ.do?uri=CELEX: 52010DC0543:EN:NOT (retrieved: 21.10.2013). 
European Commission (2012). EU regulatory fitness. Communication from the commission to the European Parliament, the council, the European economic and social committee and the committee of the regions. http://ec.europa.eu/governance/better_regulation/documents/com_2013_en.pdf (retrieved: 21.10.2013).

Frey, B. S. (1997). Not just for the money: an economic theory of motivation. Cheltenham: Edward Elgar.

Frey, B. S., \& Jegen, R. (2001). Motivation crowding theory: a survey of empirical evidence. Journal of Economic Surveys, 15, 589-611.

Gunningham, N., Grabosky, P., \& Sinclair, D. (1999). Smart regulation: Designing environmental policy. Oxford: Oxford University Press.

Hammoudi, A., Hoffman, R., \& Surry, Y. (2009). Food safety standards and agri-food supply chains: An introductory overview. European Review of Agricultural Economics, 36, 468-478.

Hirschauer, N., \& Zwoll, S. (2008). Understanding and managing behavioural risks-the case of malpractice in poultry production. European Journal of Law and Economics, 26, 27-60.

Hirschauer, N., Bavorová, M., \& Martino, G. (2012). An analytical framework for a behavioural analysis of non-compliance in food supply chains. British Food Journal, 114, 1212-1227.

Hobbs, J. E. (2004). Information asymmetry and the role of traceability systems. Agribusiness, 20, 397-415.

Kirkpatrick, C., \& Parker, D. (2007). Regulatory impact assessment: Towards better regulation. Cheltenham: Edward Elgar.

Martino, G., \& Perugini, C. (2006). Hybrid forms in food supply. In J. Bijman, O. Omta, J. Trinekens, J. Wijnands, \& E. Wubben (Eds.), International agri-food chains and networks: management and organizations (pp. 287-301). Wageningen: Wageningen Academic Publishers.

Ménard, C., \& Valceschini, E. (2005). New institutions for governing the agri-food industry. European Review of Agricultural Economics, 32, 421-440.

Miron, A. M., \& Brehm, J. W. (2006). Reactance theory-40 years later. Zeitschrift für Sozialpsychologie, 37, 9-18.

Murphy, K. (2008). Enforcing tax compliance: To punish or persuade? Economic Analysis and Policy, 38, $113-135$.

Ostrom, E., \& Walker, J. (2003). Trust and reciprocity: Interdisciplinary lessons from experimental research. New York: Russell Sage.

Picciotto, S., \& Campbell, D. (2002). New directions in regulatory theory. Oxford: Blackwell.

Pinstrup-Andersen, P. (2005). Ethics and economic policy for the food system. American Journal of Agricultural Economics, 87, 1097-1112.

Tyler, T. R. (2006). Why people obey the law. Princeton: Princeton University Press.

Unnevehr, L. J., \& Jenson, H. H. (1999). The economic implications of using HACCP as a food safety regulatory standard. Food Policy, 24, 625-635.

Widdows, R. (2000). Book review of not just for the money: an economic theory of motivation (Frey, B.S. 1997). Journal of Financial Counseling and Planning, 11, 77-78.

Williamson, O. E. (1985). The economic institutions of capitalism: Firms, markets. New York: Relational Contracting. 